Research Paper

\title{
Intraoperative Transfusion of Red Blood Cell Units Stored >14 Days is Associated with an Increased Risk of Prosthetic Joint Infection
}

\author{
Eduard Tornero ${ }^{\natural}$, Arturo Pereira ${ }^{2}$, Misericordia Basora ${ }^{3}$, Luis Lozano ${ }^{1}$, Laura Morata ${ }^{4}$, Ernesto \\ Muñoz-Mahamud ${ }^{1}$, Andreu Combalia ${ }^{1}$, Alex Soriano ${ }^{4}$ \\ 1. Department of Traumatology and Orthopedic Surgery, Hospital Clinic of Barcelona. IDIBAPS. Universitat de Barcelona \\ 2. Service of Hemotherapy and Hemostasis, Hospital Clinic of Barcelona \\ 3. Service of Anaesthesiology, Hospital Clinic of Barcelona. \\ 4. Service of Infectious Diseases. Hospital Clinic of Barcelona, University of Barcelona, IDIBAPS. Barcelona Spain. asoriano@clinic.ub.es \\ $\square$ Corresponding author: Eduard Tornero, Department of Traumatology and Orthopedic Surgery, Hospital Clinic of Barcelona. IDIBAPS. C/Villarroel 170, \\ 08036 Barcelona, Spain. Telph: +34932275533 // Fax: +34934514438; email: etornero@clinic.cat
}

(C) Ivyspring International Publisher. This is an open access article distributed under the terms of the Creative Commons Attribution (CC BY-NC) license (https://creativecommons.org/licenses/by-nc/4.0/). See http://ivyspring.com/terms for full terms and conditions.

Received: 2018.09.17; Accepted: 2019.02.09; Published: 2019.03.16

\begin{abstract}
Background: The aim of the present study was to evaluate the association between prosthetic joint infection (PJI) after joint arthroplasty and the length of red blood cell (RBC) storage, timing of RBC transfusion, and the number of RBC units transfused.

Study design and Methods: All patients who underwent a primary or revision joint artrhoplasty between January 2000 and December 2012 were retrospectively reviewed. For this study, only patients who received RBC transfusions during the day of the surgery (early transfusion group) or within the first 4 days after surgery (late transfusion group) were included.

Results: A total of 9906 patients were reviewed. In the early transfusion group $(n=1153,11.6 \%)$, patients receiving 1 or $2 \mathrm{RBC}$ units (3.5\% vs $6.3 \%, \mathrm{P}=0.041)$, 3 or $4 \mathrm{RBC}(1.3 \%$ vs $13.3 \%, \mathrm{P}=0.004)$ or $\geq 5 \mathrm{RBC}$ units $(5.0 \%$ vs $37.5 \%, \mathrm{P}=0.026)$ had a higher $\mathrm{PJl}$ rate only when $>50 \%$ of $\mathrm{RBC}$ units transfused had been stored $>14$ days. In the late transfusion group $(n=920,9.3 \%)$ these differences were not significant. Early transfusion of RBCs stored $>14$ days was an independent variable associated with an increased risk of PJI (OR:2.50, 95\%Cl:1.44-4.33)

Conclusion: Transfusion of RBC within the first $6 \mathrm{~h}$ after joint arthroplasty was an independent variable associated with PJI risk when RBC units are stored $>14$ days. The rate of PJI increased with the number of old RBC units transfused within this critical period.
\end{abstract}

Key words: red blood cell storage, transfusion, prosthetic joint infection

\section{Introduction}

Prosthetic joint infection (PJI) is a devastating complication that occurs in $1-3 \%$ of arthroplasties. According to a recent retrospective study conducted in the United States, the frequency of PJI infection significantly increased from 2001 to 2009 1. This finding could be a consequence of the increasing number of revision ${ }^{2}$ procedures, aging population and a higher frequency of co-morbities in patients undergoing arthroplasties in recent years 3 . Identifying modifiable risk factors may guide interventions aimed at reducing the risk of PJI after joint arthroplasty.

Blood transfusion has been associated with an increased risk of surgical-site infection after cardiac 4 and orthopedic surgery 5,6. The mechanism for this deleterious effect remains unclear. Stored red blood cells (RBC) undergo a variety of biochemical and morphologic changes that impair their posttransfusion viability and biologic functions; however, the detrimental effect of such storage lesion at the 
clinical level is still a matter of debate ${ }^{7}$. We previously reported $^{8}$ an association between transfusion of old packed RBC and prosthetic joint infection in primary knee arthroplasties. Recent clinical trials in ill patients 9,10 , undergoing cardiac surgery ${ }^{11}$ or in hospitalized patients 12 did not identify any advantage of transfusing fresh versus older RBC units on survival or a composite score of morbidity and mortality. Of note, none of these trials dealt with the incidence of postoperative infection, a complication that has frequently been ascribed to RBC transfusion ${ }^{5}$.

The aim of the present study was to evaluate the association between PJI after joint arthroplasty and the duration of $\mathrm{RBC}$ storage, timing transfusion (during or after surgery) and the number of units transfused.

\section{Materials and Methods}

We retrospectively reviewed 9906 patients who underwent a primary or revision joint arthroplasty between January 2000 and December 2012. For this study, patients who received RBC transfusion(s) during the day of the surgery or within the first 4 days after surgery were included. Revision arthroplasties due to infection were excluded.

Relevant information about demographics (age and sex), site (hip, knee, shoulder, wrist or ankle), type (primary or revision) of arthroplasty, indication and duration of surgery were collected by standardized clinical data review. The number of RBC units transfused, date of transfusion and length of storage of each unit of RBC transfused were obtained from the database of our blood bank. Surgeries were performed in a non-laminar airflow operating room and all patients received prophylactic antibiotic according to a standardized protocol at our institution. Throughout the study period there were no variations in the operating theatres. After being discharged, patients were followed up according to a predetermined protocol at our hospital (one month, 3 months, 6 months and then yearly). Transfused blood consisted of pre-storage leuco-reduced RBC units stored in SAG Manitol for a maximum of 42 days. The concentration of hemoglobin that trigger RBC transfusion was $8 \mathrm{~g} / \mathrm{dL}$, although it could be higher in patients with risk factors (e.g. coronary heart disease) or poor tolerance to anemia.

Primary end-point was PJI within the first year after surgery defined according to the Musculoskeletal Infection Society criteria ${ }^{15}$. Time from index surgery to diagnosis of PJI was calculated and information about the microbiology was collected. The Ethical Committee of our institution approved the study.

\section{Statistics}

Categorical variables were described by absolute frequencies and percentages and were compared using the Chi-square or the Fischer's exact test when necessary. All continuous variables were expressed as median and interquartile range (IQR) and were compared by the Mann-Whitney U test. Furthermore, continuous variables were categorized according to the median value as follows: age $\leq 75$ or $>75$, duration of surgery $\leq 120 \mathrm{~min}$ or $>120 \mathrm{~min}$ and length of storage of RBC units $\leq 14$ or $>14$ days. Two groups of patients were identified: (i) those who were transfused during or within the first 6 hours after surgery (early transfusion group) and (ii) those that were transfused after the 6-hour period and during the first 4 postoperative days (late transfusion group). Both groups were categorized according to the number of $\mathrm{RBC}$ units received (1-2, 3-4 or $\geq 5$ units) and according to the mean time of storage of packed red blood cell transfused ( $\leq 14$ days vs $>14$ days). A forward stepwise logistic regression model was performed to identify independent variables associated with PJI. Goodness of fit was explored based on the Hosmer-Lemeshow test. Statistical significance was defined as a two-tailed $P<0.05$. The analysis was performed using SPSS, version 20.0 (SPSS, Inc., Chicago, IL, USA).

\section{Results}

A total of 2277 patients undergoing primary or revision joint arthroplasty and transfused with RBC units within the first four postoperative days were initially included in this study. In 1279 (56.2\%) cases, patients were transfused during or within the first $6 \mathrm{~h}$ after surgery (early transfusion group) and in 998 $(43.8 \%)$ cases, patients were not transfused during this early period, but received at least one RBC unit within the first 4 days after surgery (late transfusion group). After exclusion of 194 patients (126 and 78 in the early and late transfusion groups, respectively) in whom the intervention was a revision surgery because of previous PJI, a total of 2073 patients were finally included in the study (figure 1). The median age was 74.9 years and $1546(74.6 \%)$ were female. There were 914 (44.1\%) hip and 1117 (53.9\%) knee arthroplasties and $428(20.6 \%)$ were revision surgeries. The median duration of surgery was 105 minutes. A total of 100 $(4.8 \%)$ patients developed a PJI. Differences in baseline characteristics of patients between early and late transfusion group are displayed in table 1.

\section{Early transfusion group}

A total of 1153 patients received at least one RBC unit during or within the first $6 \mathrm{~h}$ after surgery. The main patient and surgical characteristics of this group 
are displayed in table 1 . The median number of RBCs transfused in this early period was 2 (IQR: 2 - 2) units. According to the number of transfused RBC, 259 $(22.4 \%)$ patients received 1 unit, $712(61.8 \%)$ received 2 units, $154(13.4 \%)$ received 3 or 4 units, and $28(2.4 \%)$ received 5 or more units. The median length of storage of the RBC units transfused in this group was 14 (IQR: 7.25 - 21) days.

A total of $62(5.4 \%)$ patients developed PJI within the first 365 days after surgery with a median of 23 (IQR: 14.8-37) days between surgery and PJI diagnosis. The infection was polymicrobial in 20 $(32.3 \%)$ cases and the most frequently isolated microorganisms were coagulase-negative staphylococci (24 cases, 38.7\%), Staphylococcus aureus (20 cases, 32.3\%), Escherichia coli (12 cases, 19.4\%), Pseudomonas spp (11 cases, $17.7 \%)$ and Enterococcus spp (7 cases, $11.3 \%)$.

Table 2 shows the baseline characteristics and the rate of PJI a by the number of transfused units (1-2vs 3-4 vs $\geq 5$ RBC units) according to the mean time of storage of packed red blood cell transfused $(\leq 14$ days vs $>14$ days). Figure $2 \mathrm{~A}$ clearly shows a progressive increase in the rate of PJI by increasing with the number of old RBC transfused units. Patients receiving 1 or 2 RBC units had a significantly higher PJI rate only when both units were stored for $>14$ days (3.5\% vs $6.3 \%, P=0.041)$. This difference was also present in patients that have received 3 or 4 units of RBCs $(1.3 \%$ vs $13.3 \%, P=0.004)$ or $\geq 5$ RBCs units $(5.0 \%$ vs $37.5 \%, P=0.026$ ). Due to the long study period (13 years), the role of year of surgery was also assessed: Figure 3 shows the percentage of PJI according to the

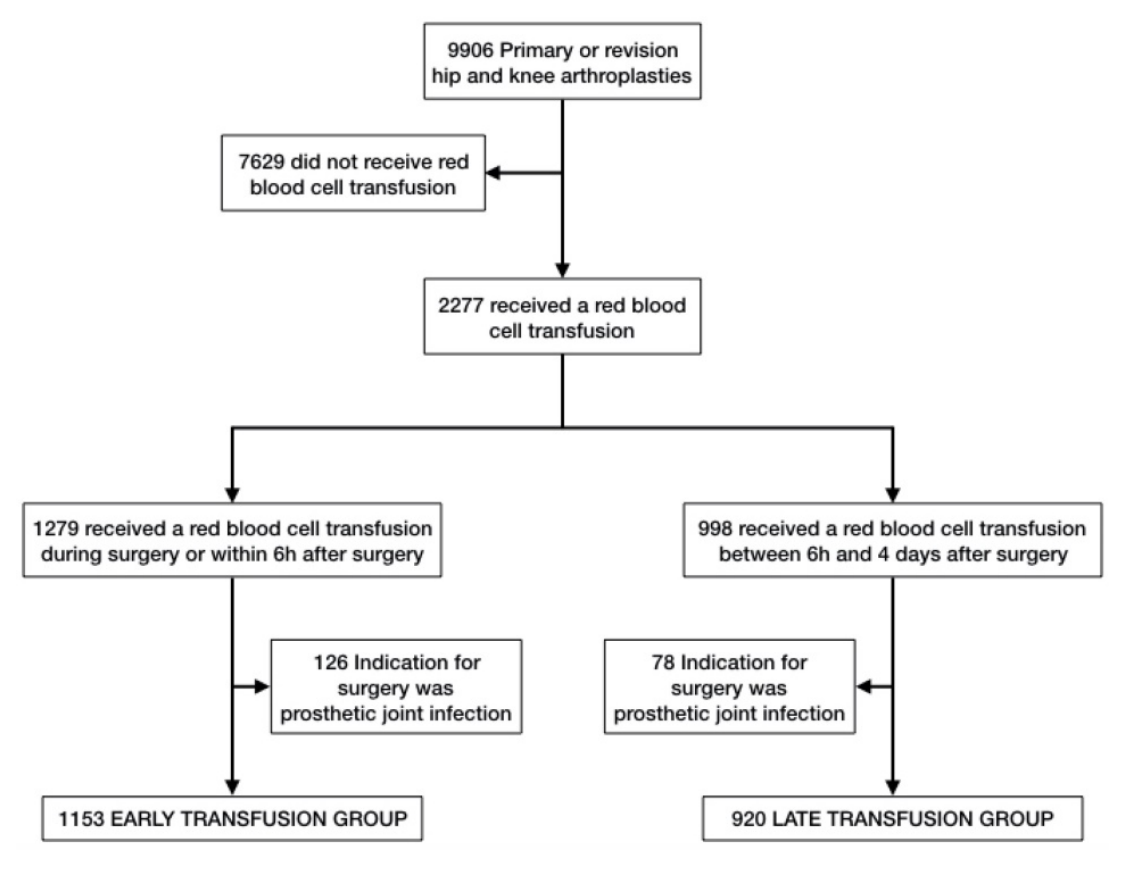

Figure 1. Flowchart of selected patients year of surgery and mean storage time of packed red blood cell transfused during first 6 hours after surgery.

Since several patient- and surgical-related risk factors for PJI were significantly different among the groups represented in table 2, we performed a multivariable binary logistic regression model including potential confounders in order to assess the independent effect of RBC units storage duration on the incidence of PJI. Covariates analyzed in the logistic regression model included the patients' sex, age, anatomical site of the arthroplasty, duration of surgery, primary vs. revision procedure, and mean time of storage and number of packed red blood cell transfused. As outlined in table 3, transfusion of packed RBC stored $>14$ days was associated with an increased rate of PJI (OR: 2.069; 95\%CI: 1.08- 3.98; $\mathrm{p}=0.0029$ ). The other factor that was associated with an increased rate of PJI was revision surgery.

\section{Late transfusion group}

A total of 920 patients did not received a blood transfusion during surgery or within the first 6 hours, but received at least one RBC unit within the first 4 days after surgery. The main patient and surgical characteristics of these patients are summarized in table 1 . Thirty-eight $(4.1 \%)$ patients were diagnosed with PJI within the first postoperative year. As shown in figure $2 \mathrm{~B}$, in this group of patients the rate of PJI did not change with the total number of transfused RBC nor with the proportion of units stored for more than 14 days, despite the overall median age of transfused RBCs was older as compared to the early transfusion group (table 1).

\section{Discussion}

To our knowledge, this is the largest study evaluating the influence of the storage time of transfused RBC on infection rate after joint arthroplasty and the first one evaluating also the timing of the transfusion. We have analyzed a large cohort of patients who underwent a joint arthroplasty and were transfused with RBC within the first four postoperative days according to whether the transfusion was performed during surgery or the first 6 hours after surgery (early transfusion group; $\mathrm{n}=1153$ ) or later than 6 hours (late transfusion group; $\mathrm{n}=920$ ). A recent, randomized trial in cardiac surgery did not find any detrimental 
effect of transfusing old RBC. However, the study did not evaluate the impact on surgical site infection and did not take into account the timing of transfusion in relation to surgery ${ }^{11}$. In contrast, a clinical trial excluding cardiac surgery (abdominal, orthopedic, vascular and urological surgeries) that randomized 199 patients to receive fresh ( $\leq 14$ storage days) or old (>14 days) RBC demonstrated that wound infections were significantly less frequent among patients receiving fresh $\mathrm{RBC}(\mathrm{RR}, 3.09 ; \mathrm{CI}, 1.17-8.18)$ 16,

\section{A. Early transfusion group}

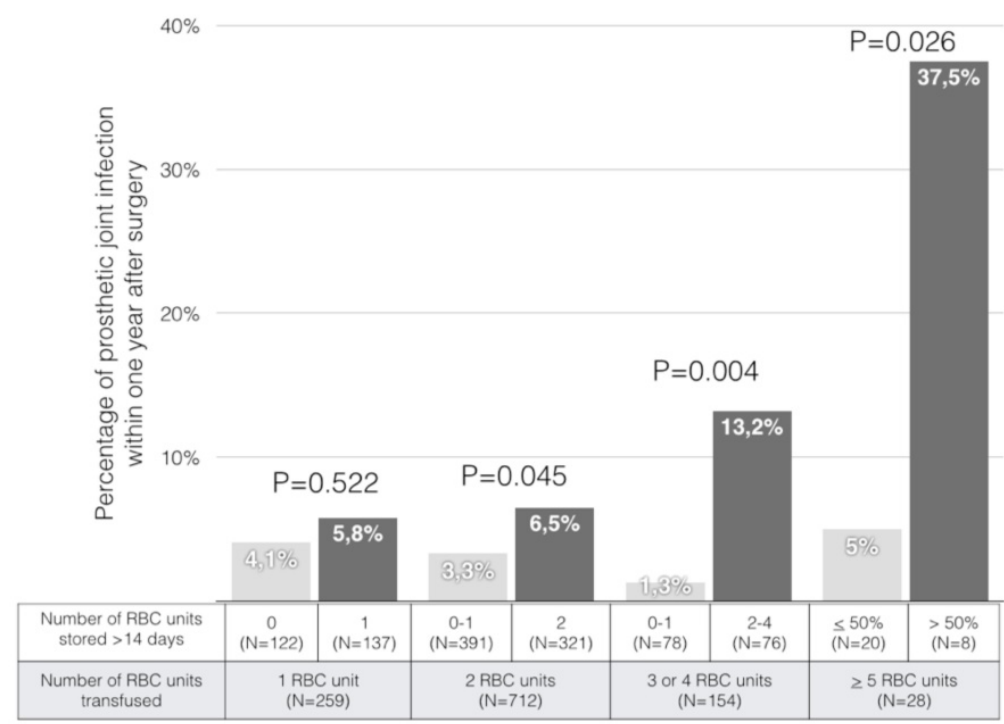

\section{B. Late transfusion group}

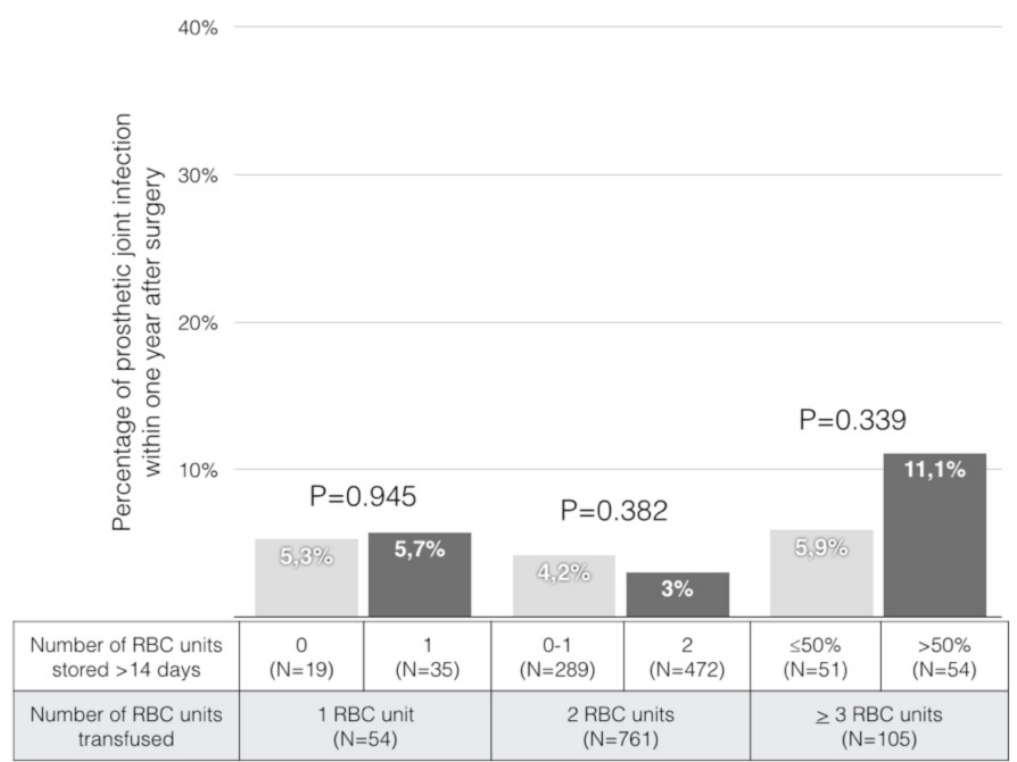

Figure 2. Rate of prosthetic joint infection within the first 365 days after joint arthroplasty according to the number of red blood cell (RBC) units transfused and the proportion of such units stored $>14$ days. (A) Patients transfused during surgery or within the first 6 hours after surgery; (B) patients transfused only later than 6 hours after surgery and up to the 4th postoperative day. however, they did not consider the timing of transfusion. Our study shows that transfusion of RBC units stored $>14$ days during surgery or early afterwards is an independent predictor of PJI (OR:2.50, 95\%CI: 1.44-4.33). The rate of PJI progressively increased with the number of old RBC units transfused during this critical period. In contrast, no differences where found among patients who received young RBC units (Figure 2A) or in those receiving older units when transfused after the $6^{\text {th }}$ postoperative hour (Figure 2B). Considering these findings together, they suggest that transfusion of old RBC units during surgery or within the first $6 \mathrm{~h}$ after surgery is harmful by itself. Storage time progressively impairs the physiological properties of red cells 17 becoming depleted of 2,3diphosphoglycerol and nitric oxide, and evolving into rigid spheroequinocytes ${ }^{8}$. Once transfused to the patient, these red cells may cause slugging and occlusion of the microcirculation ${ }^{7}$, thereby precluding a good oxygenation of the surgical wound as well as the arrival of bactericidal leukocytes and prophylactic antibiotics and increasing the deposition of free iron; factors involved in the progression from wound contamination to wound infection 17,18. Indeed, the first few hours after tissue contamination by bacteria are critical for wound infection to be established ${ }^{19}$. In agreement with our finding, events associated with damaging the phagocytic capacity of leucocytes during surgery or early postoperative period like high glucose level ${ }^{20}$, low body temperature 21 or low oxygen tissue concentration ${ }^{22}$ have been associated with a higher infection risk. These findings show that there is a "critical period" where any adverse event impacting on immune cells favors the invasion by contaminating bacteria. It is, therefore, biologically plausible that transfusion of old RBC units in this early and critical period results in more wound infections.

According to previous studies 5,23-25, male sex, surgical duration and revision surgery were risk factors associated with PJI. The influence of blood transfusion on the infection rate is always difficult to evaluate since transfusion is frequently associated with some of these risk factors (longer surgical time or revision surgery) and may act as a confounder variable. Table 2 shows that there were no 
differences between patients who received $\leq 50 \%$ or $>50 \%$ of RBC units stored $>14$ days regarding sex, duration of surgery and type of surgery despite a significantly higher PJI rate in patients receiving $>50 \%$ of old RBC units $(7.7 \%$ vs $3.3 \%, P=0.001)$.

The main limitation of our study is the retrospective nature of our work. This limitation is of particular importance since retrospective evaluation of RBC units transfused could be difficult using the medical records only. However, for the present study, the number of RBC units administered to the patients and data regarding the length of storage was obtained from the anesthesia report, medical history and matched with the database of our blood bank. Furthermore, despite the fact that patients were not randomized to receive old ( $>14$ days) or young ( $\leq 14$ days) RBC units, both groups were similar in gender, age, duration of surgery, site and type of prosthesis and this work was performed in a single institution in a uniform environment. The second limitation of our study is that the cut off used for the analysis of the storage time ( $\leq 14$ days or $>14$ days) were based on statistical parameters (median value). However, other authors in previous literature have also used this cut off point 8,26,27. The third limitation is that other parameters associated with infections like body mass index or some comorbidities such as diabetes mellitus or parameters associated with the need for RBC transfusion, such as preoperative hemoglobin, were not available.

In conclusion, transfusion of RBC units stored $>14$ days during surgery or within the first $6 \mathrm{~h}$ after surgery was a variable independently associated to PJI after joint arthroplasty. Rate of PJI increased with the number of old RBC units transfused during this critical period. If confirmed in prospective clinical trials, these results can influence on the current transfusion practice in joint arthroplasty.

Table 1. Baseline characteristics of patients according to the group of patients transfused during surgery or within the first 6 hours after surgery (early transfusion group) and group of patients transfused between 6 and 96 hours after surgery (late transfusion group).

\begin{tabular}{|c|c|c|c|}
\hline & $\begin{array}{l}\text { Early transfusion } \\
\text { group } \\
(\mathrm{N}=1153)\end{array}$ & $\begin{array}{l}\text { Late transfusion } \\
\text { group } \\
(\mathrm{N}=920)\end{array}$ & $P$-value \\
\hline Median (IQR) age (years) & $75.4(68.9-80.2)$ & $74.4(67.8-79.7)$ & 0.008 \\
\hline Female gender & $873(75.7)$ & $673(73.2)$ & 0.183 \\
\hline \multicolumn{4}{|l|}{ Site } \\
\hline Hip & $547(47.4)$ & 367 (39.9) & \multirow[t]{3}{*}{$<0.001$} \\
\hline Knee & $597(51.8)$ & $520(56.5)$ & \\
\hline Other & $9(0.8)$ & $33(3.6)$ & \\
\hline \multicolumn{4}{|l|}{ Type of prosthesis } \\
\hline Primary surgery & $837(72.6)$ & $808(87.8)$ & \multirow[t]{2}{*}{$<0.001$} \\
\hline Revision surgery & $316(27.4)$ & $112(12.2)$ & \\
\hline Fracture & $128(10.8)$ & $134(14.6)$ & 0.009 \\
\hline $\begin{array}{l}\text { Median (IQR) duration of } \\
\text { surgery (min) }\end{array}$ & $120(85-195)$ & $95(75-120)$ & $<0.001$ \\
\hline $\begin{array}{l}\text { Median (IQR) time of } \\
\text { storage (days) }\end{array}$ & $14(7.25-21)$ & $17.5(11.1-24.5)$ & $<0.001$ \\
\hline Prosthetic Joint Infection & $62(5.4)$ & $38(4.1)$ & 0.188 \\
\hline
\end{tabular}

Table 2. Baseline characteristics of patients receiving a blood transfusion during surgery or within the first 6 hours after surgery according to the number of red blood cells (RBC) units transfused and the number of RBC units stored more than 14 days.

\begin{tabular}{|c|c|c|c|c|c|c|c|c|c|c|c|c|}
\hline$N^{\circ}$ packed $R B C$ & $1-2$ & & & $3-4$ & & & $>4$ & & & all cases & & \\
\hline Categorization & $\begin{array}{l}\text { Median } \\
\leq 14 \text { days } \\
(n=498)\end{array}$ & $\begin{array}{l}\text { Median } \\
>14 \text { days } \\
(\mathrm{n}=473)\end{array}$ & p-value & $\begin{array}{l}\text { Median } \leq 14 \\
\text { days }(n=80)\end{array}$ & $\begin{array}{l}\text { Median } \\
>14 \text { days } \\
(\mathrm{n}=74)\end{array}$ & p-value & $\begin{array}{l}\text { Median } \\
\leq 14 \text { days } \\
(n=18)\end{array}$ & $\begin{array}{l}\text { Median } \\
>14 \text { days } \\
(n=10)\end{array}$ & p-value & $\begin{array}{l}\text { Median } \leq 14 \\
\text { days } \\
(n=596)\end{array}$ & $\begin{array}{l}\text { Median } \\
\text { >14 days } \\
(n=557)\end{array}$ & p-value \\
\hline $\begin{array}{l}\text { Median (IQR) age } \\
\text { (years) }\end{array}$ & $74(68-80)$ & $77(71-81)$ & 0.853 & $74(68-78)$ & $73(66-77)$ & 0.842 & $78(74-81)$ & $75(63-78)$ & 0.974 & $74(68-80)$ & $76(70-81)$ & 0.798 \\
\hline Age $>75$ years & 237 (47.6) & $274(57.9)$ & 0.001 & $35(43.8)$ & $30(40.5)$ & 0.745 & $14(77.8)$ & $5(50.0)$ & 0.210 & $286(48.0)$ & $309(55.5)$ & 0.011 \\
\hline \multicolumn{13}{|l|}{ Sex } \\
\hline Male & $115(23.1)$ & $101(21.4)$ & 0.515 & $24(30.0)$ & $32(43.2)$ & 0.088 & $7(38.9)$ & $1(10.0)$ & 0.194 & $146(24.5)$ & $134(24.1)$ & 0.862 \\
\hline Female & 383 (76.9) & 372 (78.6) & & $56(70.0)$ & $42(56.8)$ & & $11(61.1)$ & $9(90.0)$ & & $450(75.5)$ & 423 (75.9) & \\
\hline \multicolumn{13}{|l|}{ Site } \\
\hline Hip & $214(43.0)$ & $237(50.1)$ & 0.021 & $45(56.2)$ & $34(45.9)$ & 0.180 & $11(61.1)$ & $6(60.0)$ & 1.000 & $270(45.3)$ & 277 (49.7) & 0.238 \\
\hline Knee & $278(55.8)$ & 235 (49.7) & & $35(43.8)$ & $38(51.4)$ & & $7(38.9)$ & $4(40.0)$ & & $320(53.7)$ & 277 (49.7) & \\
\hline Other & $6(1.2)$ & $1(0.2)$ & & $0(0)$ & $2(2.7)$ & & - & - & & $6(1.0)$ & $3(0.5)$ & \\
\hline \multicolumn{13}{|l|}{ Type of prosthesis } \\
\hline Primary surgery & 391 (78.5) & $347(73.4)$ & 0.060 & $46(57.5)$ & $44(59.5)$ & 0.805 & $6(33.3)$ & $3(30.0)$ & 1.000 & $433(74.3)$ & $394(70.7)$ & 0.172 \\
\hline Revision surgery & $107(21.5)$ & $126(26.6)$ & & $34(42.5)$ & $30(40.5)$ & & $12(66.7)$ & $7(70.0)$ & & $153(25.7)$ & $163(29.3)$ & \\
\hline $\begin{array}{l}\text { Prosthesis indicated due } \\
\text { to fracture }\end{array}$ & $56(11.2)$ & $56(11.8)$ & 0.772 & $7(8.8)$ & $2(2.7)$ & 0.170 & $1(5.6)$ & $2(20.0)$ & 0.284 & $64(10.7)$ & $60(10.8)$ & 0.985 \\
\hline $\begin{array}{l}\text { Median (IQR) duration } \\
\text { of surgery (min) }\end{array}$ & $105(80-150)$ & $\begin{array}{l}120 \\
(85-198)\end{array}$ & 0.895 & $\begin{array}{l}135 \\
(110-180)\end{array}$ & $\begin{array}{l}137 \\
(115-198)\end{array}$ & 0.913 & $\begin{array}{l}250 \\
(145-262)\end{array}$ & $\begin{array}{l}198 \\
(160-232)\end{array}$ & 0.620 & $\begin{array}{l}115 \\
(85-170)\end{array}$ & $\begin{array}{l}125 \\
(90-198)\end{array}$ & 0.683 \\
\hline $\begin{array}{l}\text { Duration of surgery } \\
>120 \mathrm{~min}\end{array}$ & $127(37.5)$ & $175(47.8)$ & 0.006 & $40(61.5)$ & $35(62.5)$ & 0.913 & $13(86.7)$ & $35(62.5)$ & 1.000 & $180(43.0)$ & $218(50.6)$ & 0.026 \\
\hline \multicolumn{13}{|l|}{ Outcome } \\
\hline $\begin{array}{l}\text { Prosthetic Joint } \\
\text { Infection }\end{array}$ & $18(1.9)$ & $29(3.0)$ & 0.068 & $2(1.3)$ & $9(5.8)$ & 0.020 & $0(0)$ & $4(40.0)$ & 0.010 & $20(1.7)$ & $42(3.6)$ & 0.002 \\
\hline
\end{tabular}




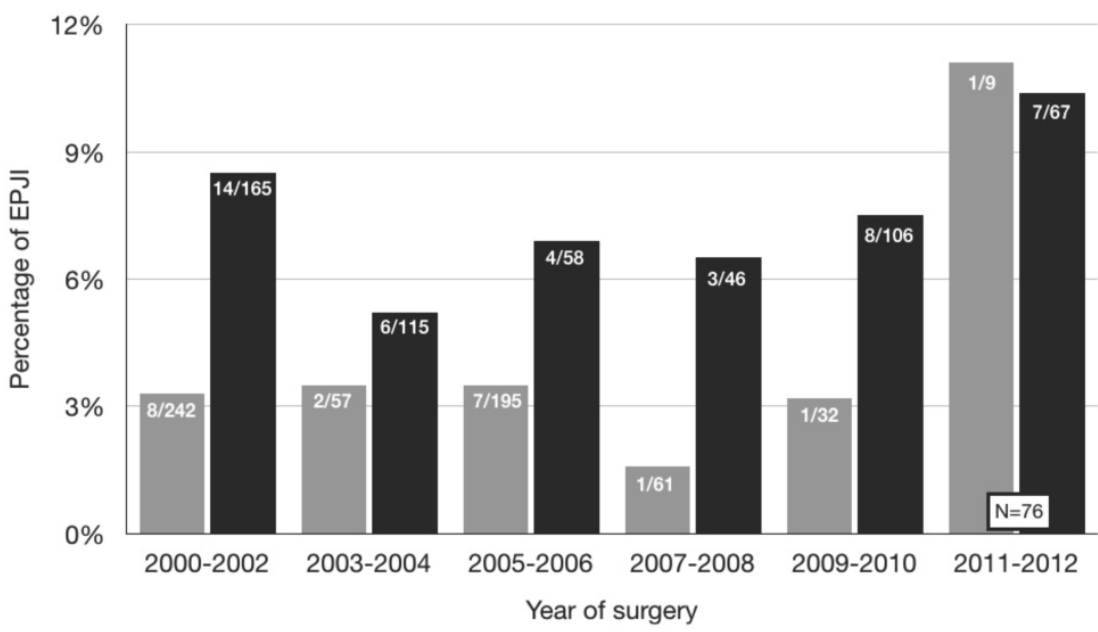

Mean time of storage of packed RBC transfused

$$
<14 \text { days } \square>14 \text { days }
$$

Figure 3. Percentage of early prosthetic joint infection (EPJI) within the first 365 days after joint arthroplasty according to year of surgery and mean time of storage ( $\leq 14$ days or $>14$ days) of packed red blood cell transfused during surgery or within the first 6 hours after surgery.

Table 3. Step-wise forward logistic regression model results of each subgroups of patients transfused during surgery or within the first 6 hours after surgery.

\begin{tabular}{llll}
\hline Multivariable analysis & p-value & OR & CI 95\% \\
\hline Age $>$ 75 years & - & - & - \\
Male gender & - & - & - \\
Site (Knee/other vs Hip) & - & - & - \\
Revision surgery & 0.001 & 2.854 & $1.54-5.29$ \\
Fracture & - & - & - \\
Duration of surgery & - & - & - \\
Mean time packed RBC storage >14 days & 0.029 & 2.069 & $1.08-3.98$ \\
Numer of packed RBC storage transfused & - & - & - \\
\hline RBC, Red blood cells; OR, Odds Ratio; CI95\%, Confidence Interval 95\%.
\end{tabular}

\section{Acknowledgement}

We thank the Hospital Clinic i Provincial de Barcelona by grant "Emili Letang 2014" and we thank the Fundación Privada Máximo Soriano Jiménez L.M. is the recipient of a PFIS grant (FI14/00230) from the Instituto de Salud Carlos III. We thank Mrs. Beatriz de la Fuente the support provided in the revision and analysis of data. Finally, we thank the cooperation provided by surgeons, physicians and nurses of the Bone and Joint Infection Unit.

\section{Competing Interests}

The authors have declared that no competing interest exists.

\section{References}

1. Kurtz SM, Lau E, Watson H, Schmier JK, Parvizi J. Economic burden of periprosthetic joint infection in the United States. J Arthroplasty. 2012;27(8 Suppl):61-5.e61. doi:10.1016/j.arth.2012.02.022

2. Jafari SM, Coyle C, Mortazavi SMJ, Sharkey PF, Parvizi J. Revision Hip Arthroplasty: Infection is the Most Common Cause of Failure. Clin Orthop Relat Res. 2010;468(8):2046-2051. doi:10.1007/s11999-010-1251-6.
3. Kurtz S, Mowat F, Ong K, Chan N, Lau E, Halpern M. Prevalence of primary and revision total hip and knee arthroplasty in the United States from 1990 through 2002. J Bone Joint Surg Am. 2005;87(7):1487-1497. doi:10.2106/ JBJS.D.02441.

4. Koch CG, Li L, Duncan AI, et al. Morbidity and mortality risk associated with red blood cell and blood-component transfusion in isolated coronary artery bypass grafting*. Crit Care Med. 2006;34(6):1608-1616. doi:10.1097/01.CCM. 0000217920.48559.D8.

5. Pulido L, Ghanem E, Joshi A, Purtill JJ, Parvizi J. Periprosthetic Joint Infection: The Incidence, Timing, and Predisposing Factors. Clin Orthop Relat Res. 2008:466(7):1710-1715. doi:10.1007/s11999-008-0209-4.

6. Everhart JS, Sojka JH, Mayerson JL, Glassman AH, Scharschmidt TJ. Perioperative Allogeneic Red Blood-Cell Transfusion Associated with Surgical Site Infection After Total Hip and Knee Arthroplasty. J Bone Joint Surg Am. 2018;100(4):288-294. doi:10.2106/JBJS.17.00237.

7. Flegel WA, Natanson C, Klein HG. Does prolonged storage of red blood cells cause harm? Br J Haematol. 2014;165(1):3-16. doi:10.1111/bjh.12747.

8. Gómez-Lesmes SP, Tornero E, Martínez-Pastor JC, Pereira A, Marcos M, Soriano A. Length of storage of transfused red blood cells and risk of prosthetic joint infection after primary knee arthroplasty. J Arthroplasty. 2014;29(10):2016-2020. doi:10.1016/j.arth.2014.06.005.

9. Lacroix J, Hébert PC, Fergusson DA, et al. Age of Transfused Blood in Critically Ill Adults. New England Journal of Medicine. 2015;372(15):1410-1418. doi:10.1056/NEJMoa1500704.

10. Cooper DJ, McQuilten ZK, Nichol A, et al. Age of Red Cells for Transfusion and Outcomes in Critically Ill Adults. N Engl J Med. 2017;377(19):1858-1867. doi:10.1056/NEJMoa1707572.

11. Steiner ME, Ness PM, Assmann SF, et al. Effects of Red-Cell Storage Duration on Patients Undergoing Cardiac Surgery. New England Journal of Medicine. 2015;372(15):1419-1429. doi:10.1056/NEJMoa1414219.

12. Heddle NM, Cook RJ, Arnold DM, et al. Effect of Short-Term vs. Long-Term Blood Storage on Mortality after Transfusion. New England Journal of Medicine. 2016;375(20):1937-1945. doi:10.1056/NEJMoa1609014.

13. Alexander PE, Barty R, Fei Y, et al. Transfusion of fresher vs older red blood cells in hospitalized patients: a systematic review and meta-analysis. Blood. 2016;127(4):400-410. doi:10.1182/blood-2015-09-670950.

14. Martí-Carvajal AJ, Simancas-Racines D, Peña-González BS. Prolonged storage of packed red blood cells for blood transfusion. Cochrane Injuries Group, ed. Cochrane Database of Systematic Reviews. 2015;12(6):55. doi:10.1002/14651858. CD009330.pub2.

15. FRCS JPM, MD TG, Infection TICGOPJ. Definition of Periprosthetic Joint Infection. Journal of Arthroplasty. 2014;29(7):1331. doi:10.1016/j.arth.2014.03. 009.

16. Spadaro S, Taccone FS, Fogagnolo A, et al. The effects of storage of red blood cells on the development of postoperative infections after noncardiac surgery. Transfusion. 2017;57(11):2727-2737. doi:10.1111/trf.14249.

17. Tinmouth A, Fergusson D, Yee IC, Hébert PC, ABLE Investigators and the Canadian Critical Care Trials Group. Clinical consequences of red cell storage in the critically ill. Transfusion. 2006;46(11):2014-2027. doi:10.1111/j.1537-2995. 2006.01026.x.

18. Hod EA, Zhang N, Sokol SA, et al. Transfusion of red blood cells after prolonged storage produces harmful effects that are mediated by iron and 
inflammation. Blood. 2010;115(21):4284-4292. doi:10.1182/blood-2009-10245001.

19. Miles AA, Miles EM, Burke J. The value and duration of defence reactions of the skin to the primary lodgement of bacteria. 1957;38(1):79-96.

20. Latham R, Lancaster AD, Covington JF, Pirolo JS, Thomas CS. The Association of Diabetes and Glucose Control With Surgical-Site Infections Among Cardiothoracic Surgery Patients. Infect Control Hosp Epidemiol. 2015;22(10):607612. doi: $10.1086 / 501830$.

21. Kurz A, Sessler DI, Lenhardt R. Perioperative Normothermia to Reduce the Incidence of Surgical-Wound Infection and Shorten Hospitalization. New England Journal of Medicine. 1996;334(19):1209-1216. doi:10.1056/NEJM199605 093341901.

22. Greif R, Akça O, Horn E-P, Kurz A, Sessler DI. Supplemental Perioperative Oxygen to Reduce the Incidence of Surgical-Wound Infection. New England Journal of Medicine. 2000;342(3):161-167. doi:10.1056/NEJM200001203420303.

23. Jämsen E, Nevalainen P, Eskelinen A, Huotari K, Kalliovalkama J, Moilanen T. Obesity, diabetes, and preoperative hyperglycemia as predictors of periprosthetic joint infection: a single-center analysis of 7181 primary hip and knee replacements for osteoarthritis. J Bone Joint Surg Am. 2012;94(14):e1011-9. doi:10.2106/JBJS.J.01935.

24. Tornero E, García-Ramiro S, Martínez-Pastor JC, et al. Prophylaxis with teicoplanin and cefuroxime reduces the rate of prosthetic joint infection after primary arthroplasty. Antimicrob Agents Chemother. 2015;59(2):831-837. doi:10.1128/AAC.03949-14

25. Mortazavi SMJ, Schwartzenberger J, Austin MS, Purtill JJ, Parvizi J. Revision Total Knee Arthroplasty Infection: Incidence and Predictors. Clin Orthop Relat Res. 2010;468(8):2052-2059. doi:10.1007/s11999-010-1308-6.

26. Koch CG, Li L, Sessler DI, et al. Duration of Red-Cell Storage and Complications after Cardiac Surgery. New England Journal of Medicine. 2008;358(12):1229-1239. doi:10.1056/NEJMoa070403.

27. Pereira A. Will clinical studies elucidate the connection between the length of storage of transfused red blood cells and clinical outcomes? An analysis based on the simulation of randomized controlled trials. Transfusion. 2012;53(1):34-40. doi:10.1111/j.1537-2995.2012.03656.x. 